\title{
A method of estimation of the caloric value of the biomass. Part II - energy balance of biomass production
}

Tomasz PISKIER, Małgorzata SMUGA-KOGUT

DOI: $10.30464 /$ jmee.2018.2.4. 311

Cite this article as:

Piskier T., Smuga-Kogut M. A method of estimation of the caloric value of the biomass. Part II - energy balance of biomass production. Journal of Mechanical and Energy Engineering, Vol. 2(42), No. 4, 2018, pp. 311-316.

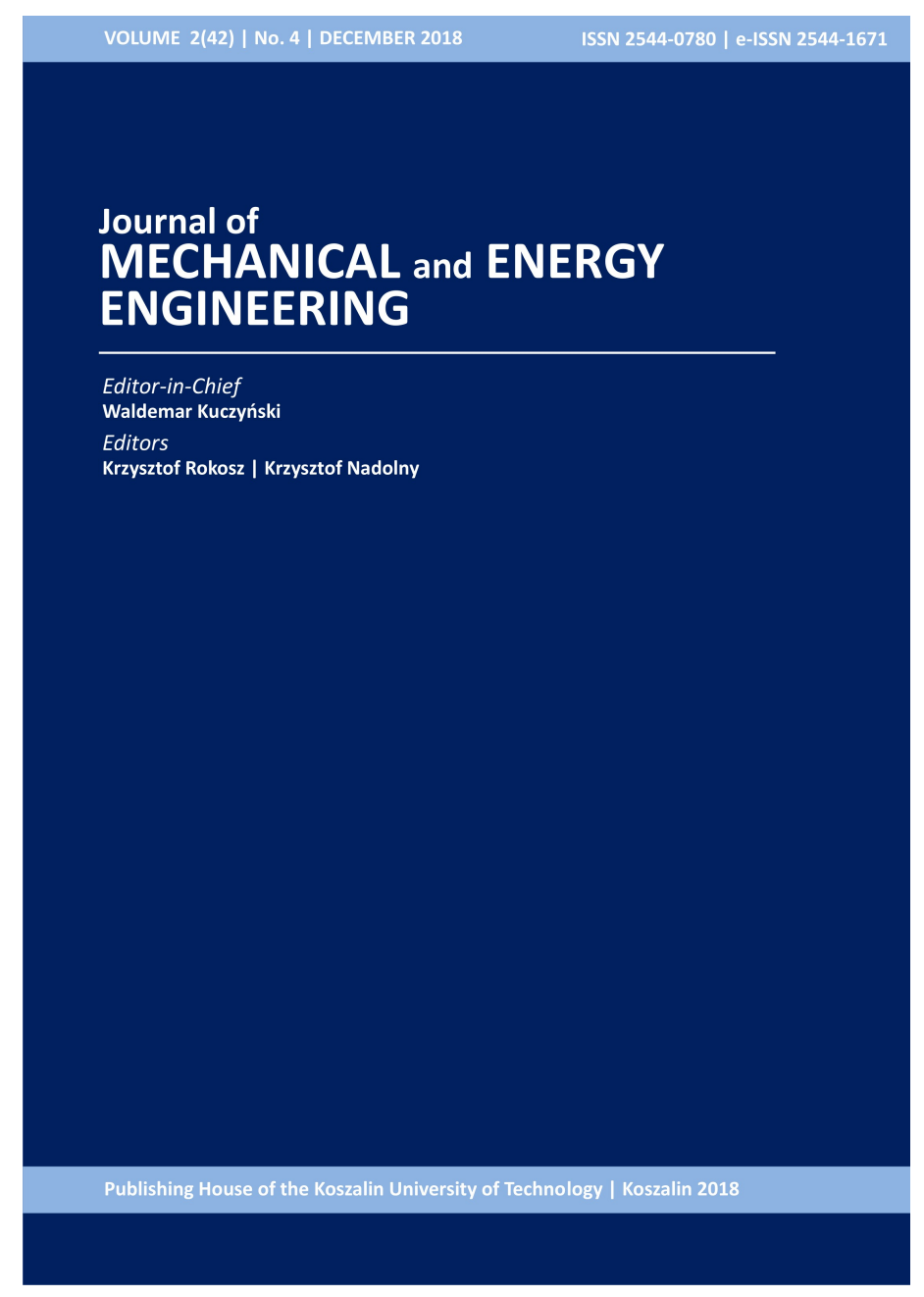

Journal of Mechanical and Energy Engineering

Website: jmee.tu.koszalin.pl

ISSN (Print): 2544-0780

ISSN (Online): 2544-1671

Volume: 2(42)

Number: 4

Year: 2018

Pages: 311-316

Article Info:

Received 10 November 2018

Accepted 14 December 2018

\section{Open Access}

This article is distributed under the terms of the Creative Commons Attribution 4.0 (CC BY 4.0) International License (http://creativecommons.org/licenses/by/4.0/), which permits unrestricted use, distribution, and reproduction in any medium, provided you give appropriate credit to the original author(s) and the source, provide a link to the Creative Commons license, and indicate if changes were made. 


\title{
A METHOD OF ESTIMATION OF THE CALORIC VALUE OF THE BIOMASS. PART II - ENERGY BALANCE OF BIOMASS PRODUCTION
}

\author{
Tomasz PISKIER $^{1^{*}}$, Małgorzata SMUGA-KOGUT ${ }^{1}$ \\ ${ }^{1 *}$ Faculty of Mechanical Engineering, Department of Agrobiotechnology, Koszalin University of Technology, \\ Racławicka 15-17, 75-620, Koszalin, Poland, e-mail: tomasz.piskier@tu.koszalin.pl
}

(Received 10 November 2018, Accepted 14 December 2018)

\begin{abstract}
When establishing a plantation of energy crops, a number of decisions regarding planned technology and plant selection should be made. Using the complex calculation algorithms, it is possible to determine the amount of energy needed to establish, run and liquidate the plantation. An analysis of the technological process and the specifics of the examined plants allows to determine the set of the most important features determining the yield size, and ultimately the energy efficiency of the planned production. When conducting field production, the influence of climatic conditions should also be taken into account, for example using a hydrothermal coefficient. The most difficult element of the planned project is to determine the size of the expected yield. Using the above relationships, a mathematical model can be used which, while maintaining the range of the system variables, allows to determine the amount of the expected energy value of the crop.
\end{abstract}

Key words: biomass, calculation of biomass production energy efficiency, modeling

\section{INTRODUCTION}

The research results presented in the literature and published studies on the methods of energy inputs calculating refer to the assessment of conducted or completed biomass production. Only sporadically, there are algorithms that allow to perform theoretical calculations of energy inputs before plantation establishing [22]. However, they contain significant simplifications concerning e.g. fuel consumption, machine performance, etc. Comprehensively developed algorithms will allow optimization of biomass production technologies, which according to many authors is a particularly important issue $[9,18,19]$.

Optimization of technological processes is possible only after recognizing and understanding the depende-ncies occurring in them. The undertaking of optimiza-tion measures is often preceded by the construction of models. Creating the models including biological pro-cesses is a complicated problem. Currently, two groups of models are created most often. The first group contains the models concerning the relationship between the conditions of the habitat and the yielding of plants, the second group are models concerning the optimization of technological processes. Model presented by Cabelguenne [3] refers to the growth and yield of maize, sunflower, sorghum, wheat under water and nitrogen stress. Villalobos [24] developed a simulation model of sunflower cultivation using, for example, the physio-logical properties of this plant. The model is corrected on a current basis based on up-to-date meteorological data. A similar model was created by Lòpez-Cedròn [12] defining the yield of maize biomass and grains in the aspect of water deficit. The model gives good results when it is possible to adjust the input factors, in this case the watering. Complex models are also created, e.g. APSIM developed for many plant species [21]. This model makes it possible to determine the yield of plants based on their physiological features, growth conditions, e.g. soil conditions, humidity, availability of nitrogen. In addition, photoperiodism, the type of photosynthesis, etc. are taken into account. The model aims to create general principles that would allow to 
obtain a satisfactory result with the introduction of lower number of data.

Attempts are made to construct the models that can determine the relationship between the size of energy inputs and crop yields. The verifiability of these models is possible provided they are used in objects with controlled atmosphere, which in practice is limited to greenhouse crops [5]. Some models are also introduced in case of biomass obtaining for energy purposes. Most often, these are the IBSAL [11] and MILP models [8].

The IBSAL method concerns an application of a mathematical apparatus for the analysis and optimization of complex biomass supply systems, optimization of harvesting, storage and processing networks. It can be considered that this method optimizes, in economic and energy terms, the logistics of biomass obtaining and processing. The MILP method makes it possible to determine the conditions under which transport of waste biomass from forestry production is profitable. This depends on the dispersion of biomass sources, production volume, transport distances, biomass transport and processing manners. Similarly to the previous method, it deals with the broadly understood logistics of biomass harvesting and processing. The optimization is based on an economic or energy calculation.

Summing up, it can be concluded that the presented models allow either determining the size of the plant yield based on physiological and habitat factors, or determining the amount of energy expenditure on the logistics of biomass obtaining and processing for energy purposes. On their basis, however, it is not possible to determine the impact of energy inputs on the energy value of the crop. Therefore, it is necessary to develop a model that would allow to determine these relationships.

\section{ENERGY BALANCE OF BIOMASS OBTAINING}

When performing the energy balance of biomass production, its basic components should be determined, i.e., the energy value of the yield and the amount of energy necessary to produce it. The methods of an evaluation of crop energy value are discussed in detail in the article "A method of estimation of the caloric value of the biomass. Part I - biomass energy potential" [14].

When assessing the energy consumption of biomass production technology, a method of process analysis can be used, which involves determining a sequence of subsequent treatments and technological operations. Then, the total energy expenditure is determined [22].

In practice, it is good to divide the technological process of production into individual stages and evaluate them separately. Typical stages that can be distinguished are as follows:

- establishing a plantation,
- running a plantation (e.g. care, fertilization),

- harvesting,

- liquidation of the plantation.

The energy expenditures incurred for establishing a plantation are quite large, especially in the case of perennial crops. For this reason, they should be accounted for proportionally over all years of plantation use or all collection cycles - if the harvest occurs every few years (e.g. basket willow). A similar rule applies to energy expenditures incurred for the liquidation of plantation.

When conducting the energy evaluation of a technological treatment, it can be performed using two methods. When the planned treatment is evaluated, the tabular values for, e.g. machine performance should be used. These capacities should be selected according to the area of the field on which the treatment will be performed. The Muzalewski's study can be used in this case [13]. Such an approach generates some inaccuracies, however, it is usually sufficient at the planning stage. When assessing the actually used technology or single treatment, it is advisable to perform direct measurements. Machine performance should be determined using simplified timing. This method is more accurate, but it can only be used on existing plantations.

Some examples of algorithms used in the evaluation of agrotechnical procedures are presented below. Sewage sludge fertilization is often used in the energy plant production technology. The relationships presented by formulas (1), (2), (3) can be used when calculating the efficiency of the fertilizer set [15]:

$$
\begin{gathered}
t_{o}=t_{z}+t_{r}+t_{j}+t_{w}, \\
t_{z}=\frac{Q_{r}}{W_{z a}}, \\
t_{r o}=\frac{Q_{r}}{q_{o b} \cdot B \cdot v_{r o}} .
\end{gathered}
$$

The number of transport means needed to receive the crop is calculated from the formula (4) [10]:

$$
i_{t}=\frac{W_{s} \cdot Q_{p}}{G_{p s}} \cdot\left(\frac{S}{v_{1}}+\frac{S}{v_{2}}+t_{w s}\right)+1 .
$$

The time required to mow the crop is calculated from the formula (5):

$$
t_{z b}=\frac{t_{o p} \cdot Q_{p}}{G_{p s} \cdot i_{t}} .
$$

Determining the amount of energy expenditure of a given treatment, the value of energy brought in by the used aggregate is taken into account, calculating it separately for the tractor and the cooperating machine, then adding the components obtained.

The energy input of the tractor's work is calculated using the formula 6 [1], individual energy 
consumption indices were adopted according to Wójcicki [23] (6):

$$
E_{c g}=\frac{M_{c} \cdot W_{e c}+Z_{c} \cdot W_{z}}{T_{n} \cdot W_{07}}
$$

The energy expenditures of the machines' operation are calculated using the formula (7) [1], unit energy consumption indices were adopted according to Wójcicki [23]:

$$
E m=\frac{M_{m} \cdot W_{e m}+Z_{m} \cdot W_{z}}{T_{n} \cdot W_{07}} .
$$

The amount of fuel consumed can be calculated using the formula (8) [7]:

$$
Q=N_{s} \cdot q \cdot h \cdot f .
$$

In practice, it is better to directly measure the amount of fuel consumed, this allows you to minimize the error. The energy expenditure of the examined technology is calculated using the formula (9) $[1,23]$ :

$$
E_{\text {tech }}=\sum E_{\text {mat }}+\sum E_{a g r}+\sum E_{p a l}+\sum E_{r} .
$$

The values of unit energy consumption indicators, presented in Table 1, are most often taken after Wójcicki [23].

The energy value of human labor is difficult to determine. Various ways of its determination and unit indices are presented in the literature on the subject. It can be assumed in some simplification, that one hour of human labor is an equivalent of $80 \mathrm{MJ}$ [6].

The summary in the assessment of the analyzed technologies is the energy efficiency index, which can be determined according to the formula (10) [4]:

$$
E_{e}=\frac{P_{a}}{E_{\text {tech }}} .
$$

It is most often used to compare different technologies or plants in terms of energy efficiency.

In economic practice, we are interested in the amount of energy that can be obtained from the surface unit. The parameter that applies here is the net energy value, calculated according to the formula (11) [20]:

$$
E_{n}=P_{e}-E_{\text {tech }} .
$$

\section{MATHEMATICAL MODEL}

Summary and generalization of energy dependencies in the production of biomass is the development of mathematical models of its cultivation. The creation of models makes it possible to estimate the energy value of the crop depending on pre-determined factors. When developing the model, it is very important to correctly determine the relationships between the examined traits and the plant yield and its energy value and to select the determinants.
An example of modeling in biomass production can be the model proposed by Piskier [16] for an evaluation of the energy value of topinambour grown for fuel.

Data for model development were collected in 2005-2009. The amount of energy inputs and the energy value of topinambour yield were determined according to the method proposed by Piskier [14] and the relationships given above. Rainfall and temperature were monitored throughout the duration of the experiment. The parameter synthetically describing the relation between rainfall and temperature is a hydrothermal coefficient, calculated according to the dependence proposed by Bartoszek and Banasiewicz [2], formula (12):

$$
W s p_{H T}=\frac{P \cdot 10}{\sum t} .
$$

Detailed studies showed a significant relationship between the topinambour yield and the hydrothermal coefficient value determined during the growing season, i.e., from May to October, for this reason it was included in the model.

The characteristics of the research object were adopted after Polański [17].

The research object was biomass (topinambour), the following were accepted as input values:

- value of cumulated energy used for establishing a plantation (proportionally to the period of its use),

- value of cumulated energy used for plantation fertilizing,

- value of cumulated energy used for plantation care,

- value of hydrothermal coefficient for the period of topinambour intensive growth (May-October).

The energy inputs included energy introduced in four streams:

- in the form of aggregates,

- in the form of fuel,

- in the form of materials,

- in the form of human labor.

The variables representing system properties are shown in Table 2.

The form of the model included an effect of: energy inputs incurred for the establishment of the plantation, its fertilization, care and hydrothermal coefficient on the yield energy value formula (13):

$$
E_{p}=f\left(E_{z a t}, E_{n a}, E_{p i e l}, W s p_{H T}\right) .
$$

On the basis of theoretical considerations and the data analysis carried out, a linear-quadratic algebraic model with a quadruple interaction was adopted as the model, which after the creation and calculation of coefficients assumed the form of formula (14): 
Tab. 1. List of unit energy consumption indicators

\begin{tabular}{|c|c|c|c|c|}
\hline & Indicator & Symbol & Unit & Value \\
\hline \multicolumn{5}{|c|}{ Investment measures } \\
\hline 1. & Tractors & $W_{e c}$ & $\mathrm{MJ} \cdot \mathrm{kg}^{-1}$ & 125 \\
\hline 2. & Machines & $W_{e m}$ & $\mathrm{MJ} \cdot \mathrm{kg}^{-1}$ & 110 \\
\hline 3. & Tractor tools & $W_{e n}$ & $\mathrm{MJ} \cdot \mathrm{kg}^{-1}$ & 100 \\
\hline 4. & $\begin{array}{l}\text { Spare parts and materials } \\
\text { for repairs }\end{array}$ & $W_{z}$ & $\mathrm{MJ} \cdot \mathrm{kg}^{-1}$ & 85 \\
\hline \multicolumn{5}{|c|}{ Materials } \\
\hline 1. & Nitrogen fertilizers & $E_{N A}$ & $\mathrm{MJ} \cdot \mathrm{kg}^{-1} \mathrm{~N}$ & 77 \\
\hline 2. & Potassium fertilizers & $E_{N K}$ & $\mathrm{MJ} \cdot \mathrm{kg}^{-1} \mathrm{~K}_{2} \mathrm{O}$ & 10 \\
\hline 3. & Phosphorus fertilizers & $E_{N P}$ & $\mathrm{MJ} \cdot \mathrm{kg}^{-1} \mathrm{P}_{2} \mathrm{O}_{5}$ & 15 \\
\hline 4. & Pesticides & $E_{p}$ & MJ $\cdot \mathrm{kg}^{-1}$ s.a. & 300 \\
\hline \multicolumn{5}{|c|}{ Direct energy carrier } \\
\hline 1. & Diesel fuel & $W_{p}$ & $\mathrm{MJ} \cdot \mathrm{kg}^{-1}$ & 48 \\
\hline
\end{tabular}

Tab. 2. Variables representing system properties [16]

\begin{tabular}{|c|c|c|c|}
\hline Symbol & Specification & Unit & Range \\
\hline \multicolumn{4}{|c|}{ Resulting factor } \\
\hline$E_{p}$ & Energy value of the crop & $\mathrm{GJ} \cdot \mathrm{ha}^{-1}$ & $63.44 \div 109.56$ \\
\hline \multicolumn{4}{|c|}{ Examined factors } \\
\hline$E_{z a t}$ & $\begin{array}{l}\text { Energy inputs incurred for the establishment of the } \\
\text { plantation (proportionally to the period of its use) }\end{array}$ & $\mathrm{GJ} \cdot \mathrm{ha}^{-1}$ & $1.00 \div 1.11$ \\
\hline$E_{n a}$ & Energy inputs incurred for plantation fertilizing & GJ $\cdot \mathrm{ha}^{-1}$ & $11.91 \div 13.97$ \\
\hline$E_{\text {piel }}$ & Energy inputs incurred for plantation care & $\mathrm{GJ} \cdot \mathrm{ha}^{-1}$ & $1.10 \div 1.65$ \\
\hline$W s p_{H T}$ & Hydrothermal coefficient & & $1.497 \div 2.527$ \\
\hline
\end{tabular}

$E_{p}=0.168+1.061 \cdot E_{z a t}-2.913 \cdot E_{n a}+0.583 \cdot E_{p i e l}+0.537 \cdot W s p_{H T}+1.551 \cdot E_{z a t}{ }^{2}-0.890 \cdot E_{n a}{ }^{2}+1.001 \cdot$

$E_{p i e l}{ }^{2}-1.968 \cdot W_{s p_{H T}}{ }^{2}+4.231 \cdot E_{z a t} \cdot E_{n a}+0.759 \cdot E_{z a t} \cdot E_{p i e l}+1.101 \cdot E_{z a t} \cdot W s p_{H T}+4.400 \cdot E_{n a} \cdot E_{p i e l}+$

$2.753 \cdot E_{n a} \cdot W s p_{H T}-0.436 \cdot E_{p i e l} \cdot W s p_{H T}+6.129 \cdot E_{z a t} \cdot E_{n a} \cdot E_{p i e l}+9.105 \cdot E_{z a t} \cdot E_{n a} \cdot W s p_{H T}-0.883 \cdot E_{z a t}$.

$E_{p i e l} \cdot W s p_{H T}-0.637 \cdot E_{n a} \cdot E_{p i e l} \cdot W s p_{H T}-7.282 \cdot E_{z a t} \cdot E_{n a} \cdot E_{p i e l} \cdot W s p_{H T}$ 
An effect of selected input factors on the energy value of the crop is presented in Figure 1.

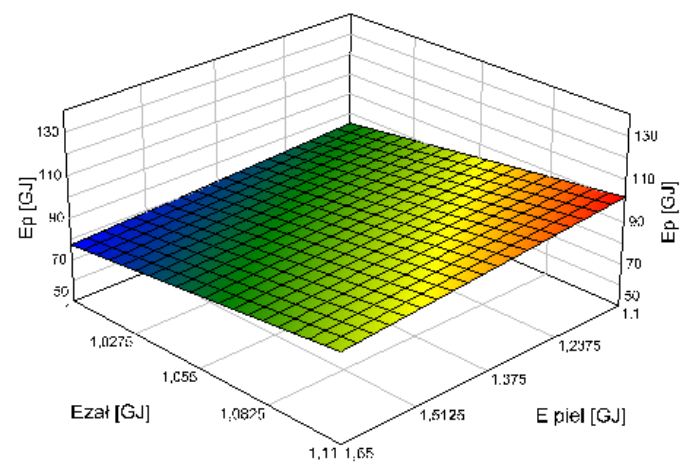

Fig. 1. An effect of changes in the value of energy expenditure incurred on the establishment $\left(E_{z a t}\right)$ and the care of plantation $\left(E_{\text {piel }}\right)$ on the energy value of the yield. Source: Piskier [16]

Theoretical and empirical research results from 2008, 2009 were used for the practical verification of the model. The energy value of the crop obtained in 2008 was $76.54 \mathrm{GJ} \cdot \mathrm{ha}^{-1}$. By substituting the actual energy inputs made in the analyzed input factors, while maintaining the hydrothermal coefficient value for a given research period, the calculated yield was $82.28 \mathrm{GJ} \cdot \mathrm{ha}^{-1}$. For data from 2009 , the model was more accurate. Empirically determined energy value of the crop amounted to $78.85 \mathrm{GJ} \cdot \mathrm{ha}^{-1}$, while the computational volume was $77.39 \mathrm{GJ} \cdot \mathrm{ha}^{-1}$. The obtained values are within the confidence interval at $\alpha=0.05$.

\section{CONCLUSIONS}

1. Analysis of energy inputs is a tool enabling decision making regarding the selection and application of biomass production technologies.

2. When developing mathematical models of biomass production, deterministic features and their impact on crop yield should be determined.

3. The proposed model makes it possible to determine the energy value of the topinambour yield grown for fuel.

4. The application of the model makes it possible to determine the impact of energy expenditure incurred on the establishment of the plantation, its fertilization and care as well as the hydrothermal coefficient on the energy value of topinambour yield.

\section{Nomenclature}

Symbols
$B \quad-$ working width, m
$E_{c g} \quad-$ energy input of the tractor's work, $\mathrm{MJ} \cdot \mathrm{ha}^{-1}$
$E_{e} \quad-$ energy efficiency index
$E_{n} \quad-$ net energy value, MJ $\cdot \mathrm{ha}^{-1}$

$E_{\text {tech }} \quad$ - energy expenditure of the examined technology, $\mathrm{MJ} \cdot \mathrm{ha}^{-1}$

$f \quad-$ engine load indicator during the treatment,

$G_{p s} \quad-$ load capacity of the trailer, $\mathrm{m}^{3}$

$h \quad-$ time needed to perform the treatment, $\mathrm{h}$

$i_{t} \quad-$ number of transport means needed to receive the crop, pes.

$M_{c} \quad-$ total weight of tractors used for a given treatment, $\mathrm{kg}$

$N_{s} \quad$ - nominal power of the engine, $\mathrm{kW}$

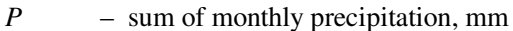

$P_{e} \quad-$ energy value of the crop, $\mathrm{MJ} \cdot \mathrm{ha}^{-1}$

$Q \quad$ - amount of fuel consumed, $\mathrm{kg}$

$q \quad-$ unit fuel consumption by the engine, $\mathrm{kg} \cdot \mathrm{kWh}^{-1}$

$q_{o b} \quad$ - sludge dose, $\mathrm{kg} \cdot \mathrm{m}^{-2}$

$Q_{p} \quad$ - biomass yield, $\mathrm{m}^{3} \cdot \mathrm{m}^{-2}$

$Q_{r} \quad$ - loading capacity of the spreader, $\mathrm{kg}$

$S \quad$ - route of transport, $\mathrm{m}$

$t_{j} \quad-$ time of passing without load, $\mathrm{h}$

$T_{n} \quad-$ normative number of working hours of the tractor during its use, $\mathrm{h}$

$t_{o} \quad-$ time of transport mean cycle (spreader), $\mathrm{h}$

$t_{o p} \quad-$ time of cycle of transport mean receiving the crop, $\mathrm{h}$

- time of passing with load, $\mathrm{h}$

- unloading time, $\mathrm{s}$

$t_{r o}=t_{w}-$ time of sludge spreading on the field, $\mathrm{h}$

$v_{r o} \quad$ - spreading rate, $\mathrm{m} \cdot \mathrm{h}^{-1}$

$v_{l}, v_{2} \quad$ - travel rate with and without load, $\mathrm{m} \cdot \mathrm{s}^{-1}$

$W_{s} \quad$ - forage harvester efficiency, $\mathrm{m}^{2} \cdot \mathrm{s}^{-1}$

$W_{e c} \quad-$ indicator of unit energy consumption of tractors, $\mathrm{MJ} \cdot \mathrm{kg}^{-1}$

$W s p_{H T}$ - hydrothermal coefficient

$W_{z a} \quad-$ load efficiency, $\mathrm{t} \cdot \mathrm{h}^{-1}$

$W_{z} \quad$ - indicator of unit energy consumption of spare parts, $\mathrm{MJ} \cdot \mathrm{kg}^{-1}$

$W_{07} \quad$ - operational efficiency of the aggregate during the given treatment, $\mathrm{ha} \cdot \mathrm{h}^{-1}$

$Z_{c} \quad-$ mass of spare parts used in the tractor, $\mathrm{kg}$

$\Sigma E_{a g r}-$ sum of energy expenditures of the aggregates used, $\mathrm{MJ} \cdot \mathrm{ha}^{-1}$

$\Sigma E_{\text {mat }}-$ sum of energy expenditures of the materials used, $\mathrm{MJ} \mathrm{ha}^{-1}$

$\Sigma E_{p a l}-$ sum of energy expenditures of the fuel consumed, $\mathrm{MJ} \mathrm{ha}^{-1}$

$\Sigma E_{r} \quad-$ sum of energy expenditures of the human labor, MJ'ha ${ }^{-1}$

$\Sigma t \quad-$ sum of average daily air temperatures from a given month, $\mathrm{C}^{\mathrm{O}}$

\section{REFERENCES}

1. Anuszewski R., Pawlak J., Wójcicki Z., (1979). Energy consumption of agricultural production. Part $I$. Methodology of research on energy consumption of production of food raw materials, IBMER Warsaw.

2. Bartoszek K., Banasiewicz I. (2007). Agrometeorological characteristics of the vegetation period in 2005 against the background of the period of 1951-2005 in the Lublin region. Acta Agrophysica, Vol. 9, No. 2, pp. 275-283.

3. Cabelguenne M., Debaeke P., Bouniols A. (1999). EPIC phase, a version of the EPIC model simulating the effects of water and nitrogen stress on biomass and yield, taking 
account of developmental stages: validation on maize, sunflower, sorghum, soybean and winter wheat. Agricultural Systems, Vol. 60, No. 3, pp. 175-196.

4. Harasim A. (1997). Possibilities to compensate for the negative impact of the stand on the yield and efficiency of winter wheat production. II. Economic and energy efficiency. Pam. Put., Vol. 111, pp. 73-87.

5. Hatirli S.A., Ozkan B., Fert C. (2005). Energy input and crop yield relationship in greenhouse tomato production. Renewable Energy, Vol. 31. No. 4, pp. 427-438.

6. Hryniewicz M., Grzybek A. (2010). Comparison of energy unit consumption of cumulated willow, miscanthus and mallow growing, Modeling of energetic use of biomass (A. Grzybek, Ed.) ITP Warsaw, pp. 145-157.

7. Karwowski T. (1998). The basics of team machine use, IBMER, Warsaw.

8. Kim J., Realff M., Lee J., Whittaaker C., Furtner L. (2011). Design of biomass processing network for biofuel production using an MILP model, Biomass and bioenergy, Vol. 35. pp. 853-871.

9. Kopetz H., Jossart J.M., Ragossnicg H., Metschina C., (2007). European Biomass Statistics 2007. AEBIOM. Bruksela. pp. 73 .

10. Kuczewski J., Majewski Z. (1985). Exploitation of agricultural machinery Vol. 1., PWRiL, Warsaw.

11. Kumar A., Sokhansanj S. (2007). Switchgrass (Panicum vigratum, L.) delivery to a biorefinery using integrated biomass supply analysis and logistics (IBSAL) model, Bioresourte Technology, Vol. 98, No. 5, pp. 1033-1044.

12. López-Cedrón F.X., Boote K.J., Piñeiro J., Sau F. (2008). Improving the CERES-Maize Model Ability to Simulata Water Deficit Impact on Maize Production and Yield Components. Agronomy Journal, Vol. 100. No, 2, pp. 296-307

13. Muzalewski A. (2006). Exploitation costs of machine, Bulletin No. 21, IBMER, Warsaw.

14. Piskier T. (2017). A method of estimation of the caloric value of the biomass. Part I - biomass energy potential. Journal of Mechanical and Energy Engineering. Vol. 1(41), No. 2, pp. 189-194.

15. Piskier T. (2002). Exploitation of agricultural machinery, WUPK, Koszalin.

16. Piskier T. (2011). The model of energy value assessment for topinambour grown for fuel. Agricultural Engineering, Vol. 5, No. 1, pp. 189-195.

17. Polański Z. (1984). Planning of experience in technology, PWN Warsaw.

18. Ramsay W. (2007). Security of energy supply in the European Union International Energy Agency. Melnik, 31.05.2007.

19. Roszkowski A. 2008. Biomass versus Agriculture Agricultural Engineering, Vol. 10, No. 108, pp.. 201-208.

20. Roszkowski A. (2008). Energy efficiency of various methods of the use and biomass production. Studies and Reports IUNG and PIB, 11, Growing energy crops and the use of agricultural production space in Poland, pp. 101-112.

21. Wang E., Robertson M.J., Hammer G.L., Carberry P.S., Holzworth D., Meinke H., Chapman S.C., Hargreaves J.N.G., Huth N.I., McLean G. (2002). Development of a generic crop model template in the cropping system model APSIM. European Journal of Agronomy, Vol. 18, No. 1-2, pp. 121-140.

22. Węgrzyn A., Zając G. (2008). Selected aspects of research on energetic effectiveness of plant biomass production technology, Acta Agrophysica, Vol. 11, No. 3, pp. 799-806.

23. Wójcicki Z., (2002). Equipment and expenditure of materials and energy in development farms. IBMER Warsaw.

24. Villalobos F.J., Hall A.J., Ritchie J.T., Orgaz F. (1996). Oilcrop-sun: A development, growth, and yield model of sunflower crop, Agronomy Journal, Vol. 88, No. 3, pp. 403-415.

\section{Biographical notes}

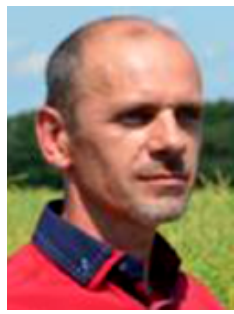

Tomasz Piskier obtained a master' degree (in 1990), and then a PhD in agronomy (in 1997) at the University of Agriculture in Szczecin. He started his scientific activity in 1990 at the University of Agriculture in Szczecin, and since 1998 he has been working as a researcher at the Koszalin University of Technology. $\mathrm{He}$ received the degree of habilitated doctor in the field of agricultural engineering at the Institute of Technology and Life Sciences in Warsaw in 2012. Currently, he is employed as an associate professor at the Department of Agrobiotechnology, of which he is the manager. His scientific interests focus on the effectiveness of renewable energy sources and soil cultivation systems. He is the author and co-author of 72 scientific articles, 4 . books and didactic publications as well as over 20 popular science articles. Has 2 patents. He participated in 4 national research projects.

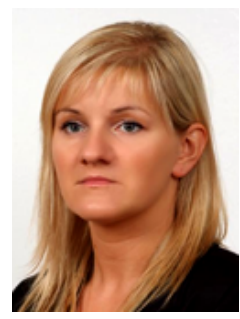

Małgorzata Smuga-Kogut obtained a $\mathrm{PhD}$ in agricultural sciences in the field of agricultural engineering in July 2014 at the Faculty of Mechanical Engineering of the Koszalin University of Technology. She works as an adjunct at the Department of Agrobio-technology at the Koszalin University of Technology. Scientific interests focus on issues related to the production of ethyl alcohol from lignocellulosic raw materials such as straw, wood, energy willow, miscanthus, biomass from agricultural wastes, as well as from food waste materials: fruit and vegetable pomace, potato industry remains, overdue food; pre-treatment of lignocellulose using imidazolic ionic liquids, ultrasound and membrane technologies.

The study was carried out as part of a research project entitled: "Production of 2nd generation bioethanol from lignocellulose biomass coming from wasteland using ionic liquids" financed by the National Science Center as part of MINIATURA 1, No. DEC- 2017/01/X/NZ9/00357. 